Twitter como instrumento de participación y deliberación. Una aproximación a su uso desde la perspectiva de la ciberdemocracia: Caso Rafael Correa

Twitter as an instrument of participation and deliberation. An approach to its use from the perspective of cyber-democracy. The Rafael Correa case

\title{
Caroline Avila
}

Universidad del Azuay Escuela de Comunicación

Docente - Investigadora en la Universidad del Azuay. PhD en Comunicación por la Pontificia Universidad de Chile.

cavila@uazuay.edu.ec

ORCID: 0000-0003-4514-4860

\section{María Belén Valdez}

Universidad del Azuay Escuela de Comunicación

Magister en Comunicación por la Universidad de Salamanca. Relacionadora Pública y Catedrática en la Universidad del Azuay.

bvaldez@uazuay.edu.ec

ORCID: 0000-0002-8112-8393

\section{Ximena Guerrero}

Universidad del Azuay Escuela de Comunicación

Master en Comunicación Institucional y Política por la Universidad de Sevilla. Técnica investigadora en la Universidad del Azuay.

xguerrero@uazuay.edu.ec

ORCID: 0000-0002-8018-9477

Fecha de recepción: 07 de mayo de 2019 / Aceptación: 02 de julio de 2019 


\section{Resumen}

Este artículo analiza el uso de las redes sociales en el campo de la comunicación política como espacios para fomentar la participación ciudadana y deliberación democrática, a lo que llamamos "ciberdemocracia". El estudio parte de la descripción de este concepto para luego aplicarlo en el análisis de la cuenta de Twitter del expresidente ecuatoriano Rafael Correa (@ MashiRafael) a fin de determinar su potencial informativo, deliberativo y participativo. Se concluye que, a pesar de ser una de las cuentas con mayor interactuación a nivel regional, su uso mantuvo limitaciones en el fomento de la participación y deliberación, elementos clave de la "ciberdemocracia."

\section{PALABRAS CLAVE}

Ciberdemocracia, redes sociales, Twitter, comunicación política, Rafael Correa.

\section{Abstract}

This article analyzes the use of social networks in the field of political communication as spaces to promote citizen participation and democratic deliberation, which we call "cyber-democracy." The study is based on the description of this concept and its application in the analysis of the Twitter account of the former Ecuadorian president Rafael Correa (@MashiRafael) to determine its informative, deliberative and participatory potential. It is concluded that in spite of being one of the accounts with the greatest interaction at the regional level, its use maintained limitations in the promotion of participation and deliberation, key elements of "cyber-democracy".

\section{KEYWORDS}

Cyber-democracy, Social networks, Twitter, Political communication, Rafael Correa.

\section{INTRODUCCIÓN}

Las plataformas digitales han revolucionado el mundo de la comunicación principalmente porque la Web 2.0 ha caducado la pasividad del espectador al incrementar la participación ciudadana, característica propia de la democracia (Menéndez, 2011). El papel de receptor pasivo ha sido remplazado por un usuario activo que crea, comparte, interactúa y participa en los procesos comunicativos.

La importancia del estudio de las redes sociales en el marco de la comunicación política radica en la medida en que estas fomentan la participación de sus usuarios dentro de los procesos informativos y políticos (Towner, 2013). Además, constituyen "espacios deliberativos monumentales" ideales para generar y promover el debate (Caldevilla, 2010).
En estos medios digitales, los ciudadanos, ahora convertidos en usuarios, hablan de lo que realmente les interesa, son ellos los que tienen la posibilidad de generar la agenda política y mediática (Hernández, 2013). Como afirma Vaca (2013), en redes sociales "cualquier persona es potencialmente un medio de comunicación sin permiso de los Estados" (p.225).

Con las redes sociales ese diálogo ahora se da bajo un techo digital construyendo lo que se conoce como "esfera pública on-line" (Posada, 2011). Parafraseando a Castells (2008), la revolución de la información ha causado que la opinión pública se globalice. Es decir, la esfera pública, la voz del pueblo que define la política de la sociedad antes construida en espacios "socio-espaciales" y a partir de los contenidos publicados por los medios de comunicación, se ha extendido a un entorno global. Se habla de una sociedad civil global, de una "ciudada- 
nía sin fronteras" que comparte y expresa valores e intereses por el bienestar universal, que manifiesta una forma de gobernanza global (Resina, 2010).

El internet y las redes sociales dan la bienvenida a comunidades virtuales y comprenden un valioso y nuevo espacio de participación política, desempeñando un papel significativo a la hora de influir en las tomas de decisiones de los gobiernos y así moldear las relaciones entre el poder ejecutivo, político, ciudadano y de otros actores sociales (Sandoval-Almazán y Gil-García, 2014). En el ciberespacio, el usuario se empodera de su papel como ciudadano para comentar y exponer su punto de vista, ante una sociedad on-line que cada vez tiene más voces y también más receptores. El ciudadano tiene ahora el poder que antes era privilegio del periodista, para cuestionar, criticar y opinar (Rodriguez y Ureña, 2011).

Esta red de e-ciudadanos que interactúan y se involucran activamente en la vida política y en las decisiones colectivas dentro de un escenario on-line es lo que llamamos "ciberdemocracia" (Sánchez, 2008). Por ser un término nuevo y ambiguo no hay consenso en su definición, sin embargo, en esta investigación seguimos a Martín (2004), quien aplica el término como una forma de democracia deliberativa o participativa frente a la democracia representativa, lo que nos permite compartir información, conectarnos y comunicarnos con una comunidad global.

El desarrollo de esta ciberdemocracia se ha valido de varios espacios para gestar sus operaciones digitales, siendo Twitter una de las piezas centrales de la llamada esfera pública virtual (Sampedro y Resina, 2010). Tras trece años de existencia, Twitter se ha consolidado como la red predilecta para informar y comunicar, ya que su naturaleza como microblogging (Calde- villa, 2010) permite un mayor flujo de contenidos en menor tiempo.

En el mundo de las relaciones políticas, esta red social ha alcanzado gran popularidad, especialmente en el momento de medir la interacción entre votantes y dirigentes (Waisbord, 2013). Matthias Lufkens (2015), en un estudio realizado para Twiplomacy, dijo que ahora las diferencias entre políticos y países se plasman en Twitter, llegando a desencadenar una suerte de "guerras de hashtag" entre embajadas y ministerios de relaciones exteriores. Según Deltell y Martínez (2014) varios intelectuales y analistas consideran que Twitter es un elemento vital para la consolidación de la democracia, de los valores sociales y de la libertad, situación que ha llegado hasta a candidatizarlo, en varias ocasiones, para el premio Nobel de la Paz (Morozov, 2012).

Este sentir no ha pasado desapercibido en la realidad política latinoamericana. Según datos de TwLat.com, en el 2013 los diez líderes más activos en Latinoamérica y en lengua castellana superaban en total los 100 millones de seguidores, contando con figuras como Hugo Chávez, Cristina Fernández de Kirchner, Dilma Rousseff, entre otros. En el caso ecuatoriano, Rafael Correa ha sido considerado una de las figuras políticas con más influencia en redes sociales. Según el ranking realizado por Twiplomacy (2015), Correa se posicionaba en el puesto \#22 de los líderes mundiales con más seguidores en Twitter, además de ser el líder latinoamericano que más conversación generaba, con un $71 \%$ de tuits de respuesta a los usuarios; a nivel mundial, Correa se encontraba en el tercer lugar de los líderes con mayor interacción on-line (Espinosa, 2011).

Estas características, así como su popularidad en la red, convirtió a Correa en el político más influyente del país en Twitter (Toral, 2013; Llo- 
rente y Cuenca, 2014), donde la personalidad del exmandatario se veía reflejada en muchos de sus mensajes. Al sentir esta cercanía, algunos ciudadanos optaban por expresar sus respectivas quejas y peticiones, a las que el expresidente gestionaba delegando el problema a la autoridad responsable. Se puede incluso decir que el entonces presidente gobernaba por medio de su cuenta de Twitter (Ávila, 2017). "Los equipos de comunicación de gobierno se ven obligados a monitorear cualquier palabra clave que les cite, tengan o no tengan Twitter y menciones" (Espinosa, 2011, p. 11).

Para Mathew Carpenter (2015), exgerente on-line de Google y de Twitter para América Latina, Ecuador era el único país en el mundo donde el sector público era más avanzado que el privado en el uso de redes sociales. "No encontré en el mundo a ningún gobierno que entendió el poder de las redes como este (de Rafael Correa)" (p. 1).

Presentado este panorama, se hace evidente el impacto nacional e internacional que mantuvo la cuenta de Twitter de Rafael Correa. Sin embargo, a la luz de los principios de deliberación y participación que implica la esfera pública digital, ¿cuánto se ha aprovechado este instrumento de comunicación y gestión para construir y fortalecer una ciberdemocracia? Esta investigación busca proporcionar un análisis descriptivo sobre el uso, las estrategias y la gestión de la cuenta de Twitter @MashiRafael.

\section{MÉTODO}

Para realizar un análisis profundo que visualice el uso que el expresidente ecuatoriano Rafael Correa dio a su cuenta de Twitter, se propuso una metodología basada principalmente en dos investigaciones "El Gobernauta Latino Americano", de Valenti et al. (2015) y "Comu- nicación Política en Redes Sociales", de María Hernández (2013). La primera plantea una matriz de relevamiento de información y una ficha metodológica que permite medir las acciones democráticas de los gobernantes en redes sociales, y la segunda complementa esta información a nivel teórico. A su vez, se apoya en la propuesta de Posada (2011) quien analiza las tecnologías integradas de comunicación - TIC, como herramientas para reconectar al electorado con sus representantes. En este estudio, Posada utilizó tres ejes como indicadores de calidad democrática aplicados en las páginas web de partidos políticos de España. Los ejes propuestos son: informativo, deliberativo y participativo.

El enfoque metodológico de este estudio es cuantitativo, dado que es un análisis de contenido, y su alcance es descriptivo. Se consideró como la unidad de análisis al tuit emitido desde la cuenta de Twitter de Rafael Correa, @MashiRafael, así como la respuesta al usuario. El tipo de muestreo es no probabilístico y se obtuvo del total de tuits generados por dicha cuenta durante el período comprendido entre el 1 de febrero y el 1 de abril ( $n=262$ ) de 20151, junto con las respuestas a los usuarios durante el período seleccionado $(n=180)$.

En una primera etapa de esta investigación, con el sustento teórico antes mencionado, se elaboró una ficha metodológica que propone las categorías e indicadores. Las variables fueron codificadas y se procedió a fichar, filtrar y categorizar los tuits.

\footnotetext{
1 Cabe recalcar que este período corresponde a los meses previos a la visita del papa Francisco a Ecuador, cuya presencia habría alterado un normal desarrollo de la comunicación por Twitter; además, a partir de mayo de 2015 en el Ecuador crecieron las manifestaciones en contra del gobernante de turno. Esta situación política alteraría los hallazgos, razón por la cual los datos se extendieron hasta abril de ese año.
} 
La estructura metodológica presentó tres componentes, cada uno correspondiente a un objetivo específico. El primer componente tuvo la finalidad de identificar los asuntos centrales, lo que permitió visualizar a qué asuntos dio preferencia el expresidente.

El segundo componente fue el de frecuencia y potencial viral. Al ser una plataforma de comunicación pública abierta y asimétrica (Orihuela, 2011), permite que los contenidos se propaguen sin limitaciones. Con excepción del límite máximo que establece Twitter, que en ese tiempo era de 140 caracteres por tuit, este medio no presenta trabas al momento de compartir información de una manera ilimitada (López, 2012). Las variables propuestas fueron: número de seguidores, número de retuits, número de favoritos, número de publicaciones diarias, cantidad de tuits.

El tercer componente tuvo la finalidad de determinar y clasificar los tipos de tuits. Para esto se establecieron las siguientes categorías propuestas por Hernández: diversidad y cantidad de información, interacción, deliberación, participación ciudadana y enfoque de la cuenta (2013, p. 61).

Esta estructura, tal como lo plantea Hernández (2013), pretende describir las oportunidades que brindó el exmandatario Rafael Correa para interactuar, deliberar con los usuarios y permitir la participación de los mismos.

\section{ANÁLISIS DE RESULTADOS}

Con el objetivo de visualizar los contenidos temáticos predominantes, se clasificaron los tuits según 26 categorías temáticas y se contabilizaron las palabras que más se repiten para comprobar los temas centrales. Los resultados del análisis evidenciaron que el expresidente dio preferencia a temas relacionados con obras, visitas y recorrido político (12\%), oposición y no simpatizantes (11\%) y comunicación medios y libertad de expresión (8\%). El análisis de contenido visualizó el uso recurrente de frases como "Somos más"; "Hasta la victoria siempre" y "Prohibido Olvidar". Es importante recalcar que un 20\% de los tuits contuvo el eslogan o hizo referencia de algún modo a Alianza PAIS o a su Revolución Ciudadana. A pesar de que la repetición de estas palabras demostró un esfuerzo por posicionar y publicitar al partido y al gobierno de Alianza PAIS, no se encontró el uso de etiquetas o hashtags en el Twitter de Rafael Correa.

El número de seguidores es considerado como un indicador del potencial viral y del potencial alcance de los contenidos (Cha, Haddadi, Benevenuto y Gummad, 2010), aunque no es el factor más relevante al hablar de la influencia de un líder político en Twitter. En el caso de la cuenta @MashiRafael, en agosto de 2015 tenía un total de 2.346 .000 seguidores $^{2}$. El promedio de retuits era de 570 y de 330 favoritos, lo que evidenciaba una media de 0,02\% y un 0,01\% de potenciales lectores que consideraban que el contenido del tuit era de interés, relevancia o "digno de ser difundido" (Alonso, Gómez, Figuerola y Cordón, 2012; Jimenez, Artero y Marcos, 2014). De acuerdo a las métricas tradicionales de análisis de Twitter, al parecer el alcance real que mantenía la cuenta @MashiRafael era bajo en proporción al alcance potencial.

La cantidad de información emitida es también otro indicador de la actividad en Twitter. De manera ilustrativa se puede decir que, para la fecha del estudio, Rafael Correa contaba con un total de 8.962 tuits, con un total de publicaciones diarias que variaban de 1 a 20 tuits. Los horarios tampoco parecían ser estables ya

2 Para la fecha de esta publicación, 2019, el total de seguidores de la cuenta llega a 3.4 millones. 
que se registraba actividad a cualquier hora del día, especialmente en las horas de la madrugada, en las cuales se generaba gran cantidad de respuestas.

El tipo de información predominante fue de "opinión". Los asuntos centrales que más se repitieron fueron: oposición o no simpatizantes con el 30\%, y comunicación, medios y libertad de expresión con el 18\%. Como se indicó, en el periodo de estudio se contabilizaron un total de 262 tuits y 182 interacciones. Es decir, un 69\% de respuestas a usuarios. Twiplomacy (2015), posicionó a Rafael Correa como el líder más conversacional de Latinoamérica y el tercero en el ranking mundial.

Al responder una mención, el expresidente no solo estaba interactuando con el usuario, sino que estaba visibilizando a aquellos usuarios que fueron respondidos, así como a sus respectivos tuits. Ante esto, surge una pregunta: ¿A qué tuits respondía el expresidente? El 56\% de respuestas a los usuarios correspondieron a quejas, solicitudes y reclamos, seguido por un alto nivel de respuesta a mensajes simpatizantes. Véase figura 1.

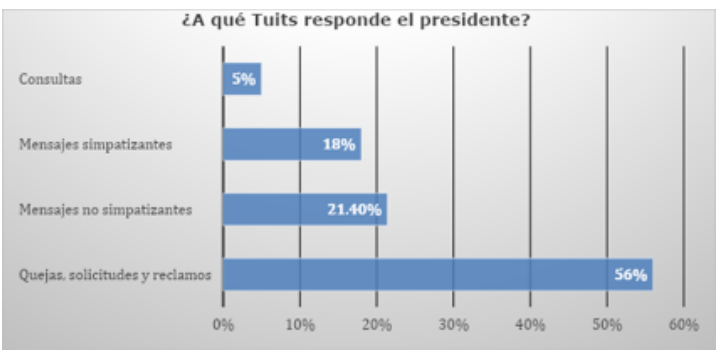

Figura 1. Porcentaje de respuestas según el tipo de mención.

Los resultados de esta investigación demostraron que la cuenta de Twitter @MashiRafael promovió pocos espacios de deliberación. El 1\% de los tuits contenía enlaces o se presentaba en forma de consulta electrónica, no se encontraron tuits con enlaces a aplicaciones, foros de debate ciudadano, encuestas electrónicas acerca de proyectos, reformas o procesos políticos.

Se pudo comprobar también que Rafael Correa no daba prioridad a su Twitter como herramienta de participación ciudadana. De los tuits que contuvieron algún enlace, tan solo un 3\% conducían a plataformas de participación ciudadana. El 1\% de los tuits contuvo enlaces a concursos o aplicaciones y no se promovió el acceso a la construcción de contenidos o peticiones en línea mediante enlaces que permitan dichas acciones.

Un 3\% de los tuits de esta cuenta invitaba a la ciudadanía a ser parte de movilizaciones y eventos públicos; y tan solo un 5,3\% de los tuits fueron redactados en forma de pregunta. Un $13 \%$ de los tuits contenían un enlace adjunto. De estos tuits, un $47 \%$ conducían a medios de comunicación y un 26\% a fotns. lo que reflejaba que predominaba un enfoque informativo.

\section{CONCLUSIONES}

Uno de los resultados que llamó la atención es el bajo promedio de audiencia activa, con más de 2 millones de seguidores (agosto de 2015), el promedio de retuits fue de tan solo 570 y de 330 favoritos, equivalentes a un 0,02\% y un 0,01\% de audiencia activa. Más allá de reflejar que no se estaba aprovechando el potencial viral y de alcance que mantenía esta cuenta, nos hace cuestionar por qué los usuarios no se identificaban o no consideraban el contenido "digno de ser difundido" (Alonso, Gómez, Figuerola y Cordón, 2012). Una de las explicaciones a este dato puede ser la hora en la que tuiteaba el exmandatario, que podía generar menor reacción en la audiencia. Otro factor era la ausencia de hashtag que, por lo general, facilita una 
mayor interacción (Suh, B., Hong, L., Pirolli, P. y Chi, E. H. 2010).

Esta investigación nos permite visualizar que Correa dio prioridad a tres asuntos: obras y recorrido político, oposición o no simpatizantes y comunicación, medios y libertad de expresión. La inmediatez y el control del mensaje hicieron que esta red sea perfecta para informar al público sobre el recorrido político. Asimismo, la rendición de cuentas es permanente y, en este caso, se mostró como una acción inherente en la vida política; por lo tanto, es común que los gobernantes hagan uso de sus redes sociales para comunicar a la ciudadanía sobre actividades que se están realizando en beneficio de la sociedad.

Un resultado característico del gobierno ecuatoriano, en la presidencia de Rafael Correa, fue el peso atribuido a asuntos referentes a la oposición, a la comunicación, medios y libertad de expresión, lo que nos permitió contemplar el constante enfrentamiento del gobierno con los grupos de oposición y los medios de comunicación. Esta confrontación también fue evidente en Twitter. La investigación demostró que un 27\% de los tuits apuntaron a la "prensa corrupta" y un $13 \%$ a opositores o no simpatizantes. El $67 \%$ de los tuits que hicieron referencia a algún sujeto fueron expresados en un tono negativo. El análisis de contenido realizado reflejó que entre las palabras más repetidas en la cuenta @MashiRafael se encontró "prensa corrupta" y "prensa mercantilista". Estos resultados advierten una posible discriminación a los medios privados (ONU critica, 2012).

Otra conclusión importante que nos permitió contemplar la gestión y la administración de la cuenta de Rafael Correa fue el porcentaje de respuesta a sus seguidores, que correspondió a un 69\% del total del contenido, situación que lo colocó como el líder más conversacio- nal en Latinoamérica. El análisis de contenido nos mostró más detalladamente que un 56\% de las menciones que recibió fue de "Quejas, solicitudes y reclamos", de las cuales un 96\% fueron respondidas y delegadas a la autoridad responsable. Se puede concluir que, en Twitter, Rafael Correa asumió su papel de primer mandatario para delegar responsabilidades y solucionar problemas específicos de la ciudadanía.

Esta forma de interacción entre el gobernante y los ciudadanos se acercó más a las prácticas del populismo latinoamericano en donde hay un fuerte y directo involucramiento con el electorado (Avila, 2017). El exgobernante ecuatoriano se caracterizó durante toda su gestión por mantener una relación cercana con la gente, lo cual se vio reflejado en la alta respuesta de las quejas que la gente le entregaba por Twitter.

Este trabajo concluye que sí existió una gestión de gobierno de Rafael Correa por Twitter, quien se mantuvo interactuando con el usuario manteniendo un uso bidireccional del medio. Aun así, en el discurso de Rafael Correa por Twitter predominaba un enfoque informativo sobre un enfoque participativo. La cantidad de tuits redactados como preguntas correspondía a un 5,3\%. Hacer una pregunta por Twitter significa abrir un espacio de participación, como mencionan Sánchez, Duarte y Rodríguez Esperanza (2013) no basta con estar presente en las redes sociales o aumentar el número de mensajes que se publican para rentabilizar política y electoralmente estas vías de comunicación. Esta característica ha sido subestimada por el expresidente ecuatoriano.

Como se ha mencionado en líneas anteriores, el nivel de retuits y favoritos era bajo con respecto al número de seguidores que mantenía la cuenta @MashiRafael. Una de estas causas pudo ser precisamente a que los mensajes 
eran redactados con el objetivo de informar o comunicar su opinión a los seguidores, en lugar de presentar el mismo contenido, pero con un enfoque más atractivo e inclusivo y que manifieste un interés por conocer la opinión pública (Toral, 2013). Otro indicador que nos permitió comprobar el enfoque informativo de la cuenta fue el predominio de enlaces a medios de comunicación, a fotos y a videos en relación con los enlaces existentes a plataformas de participación, concursos o encuestas.

No se debe subestimar la importancia de la cantidad de información que se entrega por este canal, ya que un usuario más informado está más dispuesto a participar (Posada, 2011). La cuenta de Twitter @MashiRafael sobre todo se enfoca en informar. Sin embargo, la base teórica de esta investigación propone un nuevo escenario virtual para la política, un "deber ser" de las redes sociales en un estado democrático. Este escenario demanda la existencia de espacios de deliberación y participación ciudadana. La literatura reafirma la idea que la clave de Twitter es su potencial dialógico, en el que el votante no sólo escucha, sino que también participa y opina (Criado, Martínez-Fuentes y Silván, 2013).

Para Posada (2011) este componente participativo corresponde a la máxima expresión de democracia en internet; sin embargo, es un elemento que ha sido obviado y relegado en la cuenta de Twitter del ahora expresidente de la República del Ecuador.
Este escenario de democracia virtual exige acciones importantes por parte de los gobernantes, tales como el acceso a la construcción de contenidos, la posibilidad de envíos de propuestas, la creación de foros de debates, eventos y todos aquellos esfuerzos que permitan al ciudadano empoderarse de los procesos políticos e intervenir en ellos (Hernández, 2013). A pesar de disponer de plataformas digitales que fomentaban el diálogo y el envío de propuestas en Ecuador, tal como fue www.dialogonacional. gob.ec (página creada y habilitada en julio de 2015 por la Secretaría Nacional de Planificación y Desarrollo -Senplades), en este estudio no se identificó que por medio del Twitter de Rafael Correa se promocionaba o se promovía el uso de esta herramienta.

En esta investigación se ha podido comprobar que la cuenta de Twitter de Rafael Correa no era utilizada como herramienta democrática, pero sí como una herramienta de gestión de gobierno. Es decir, mediante Twitter, el exmandatario delegaba y proponía salidas a problemas reales de la ciudadanía, esto se entiende como gestión de gobierno por Twitter. Sin embargo, no se puede hablar de una ciberdemocracia, debido a que no se han promovido los espacios ni las herramientas suficientes para que la ciudadanía se empodere activamente de los procesos políticos. 
El análisis de contenido de esta investigación nos dejó una interesante lectura que refleja lo que fue gran parte de la realidad comunicacional del país, incluso la cuenta de Twitter nos permitió contemplar las reacciones y escuchar la voz oficial del primer mandatario ante sucesos específicos. Sin embargo, mientras los gobernantes no construyan espacios para la participación y la deliberación ciudadana, y se eduque al pueblo para hacer uso de los mismos, se podrá decir que aún no se ha cumplido el "deber ser" de las redes sociales en un estado democrático.

\section{AGRADECIMIENTOS}

Las autoras agradecen al Vicerrectorado de Investigaciones de la Universidad del Azuay, así como a su Escuela de Comunicación, su apoyo en la realización del estudio y el financiamiento otorgado a través de horas de investigación en el marco de la línea de investigación de Comunicación y Política. 


\section{BIBLIOGRAFÍA}

Alonso, J., Gómez, R., Figuerola, C. \& Cordón, J. (2012). Propuesta de estudio del campo semántico de los libros electrónicos en Twitter. Scire: representación y organización del conocimiento, 18(2), 87-97.

Alonso-Muñoz, L., Miquel-Segarra, S. \& Casero-Ripollés, A. (2016). Un potencial comunicativo desaprovechado. Twitter como mecanismo generador de diálogo en campaña electoral. Obra digital: revista de comunicación, 11, 39-59.

Ávila, C. (2017). Comunicación de gobierno en el populismo latinoamericano: el caso de Rafael Correa, Ecuador. (Tesis Doctoral. Pontificia Universidad Católica de Chile, Santiago). Recuperado de https://repositorio. uc.cl/handle/11534/21604

Caldevilla, D. (2010). Democracia 2.0: La política se introduce en las redes sociales. Revista Internacional de Investigaciones Publicitarias, 3(2), 31 48.

Carpenter, M. (24 de febrero de 2015). Carpenter: Gobierno sobreestima su influencia en redes sociales. Política. (M. Cevallos, Entrevistador) Diario Universo. Recuperado 1 de abril 2016, de http://www.eluniverso. com/noticias/2015/02/24/nota/4587446/carpenter-gobierno-sobrestima-su-influencia-redes-sociales

Castells, M. (2008). The New Public Sphere: Global Civil Society, Communication, Networks and Global Governance. The Annals of the American Academy of Political and Social Science, 616(1), 78-93. doi:10.1177/0002716207311877

Cha, M., Haddadi, H., Benevenuto, F. \& Gummad, K. (2010). Measuring user influence on twitter: The million follower fallacy. Proceedings of the Fourth International AAAI Conference on Weblogs and Social Media (ICWSM 2010) (págs. 10-17). Menlo Park: CA: AAAI Press.

Criado, J.I., Martínez-Fuentes, G. y Silván, A. (2013). Twitter en campaña: las elecciones municipales españolas de 2011. Revista de Investigaciones Políticas y Sociológicas, 12(1), 93-113.

Deltell, L. \& Martínez Torres, A. G. (2014). Perfiles de los presidentes latinoamericanos en Twitter. Telos, 99, 114-125.

Espinosa, C. (4 de diciembre de 2011). Rafael Correa en Twitter: Conectar vs. discutir con el presidente. Recuperado 1 de abril 2016, de Cobertura Digital: http://www.coberturadigital.com/2011/12/04/ rafael-correa-en-twitter-conectar-vs-discutir-con-el-presidente/ 
Hernández, M. (2013). Comunicación Política en Redes Sociales. (Tesis de Maestría en Comunicación. Universidad Centroamericana José Simeón Cañas, El Salvador). Recuperado de http://www.uca.edu.sv/gescom/ wp-content/uploads/2017/03/tesis20.pdf

Jimenez, G., Artero, M. \& Marcos, R. (2014). Extracción, análisis y visualización de información social desde Twitter. Recuperado de Repositorio de la producción académica. Universidad Complutense de Madrid: http:// eprints.ucm.es/26486/1/Memoria\%20SSII.pdf

LLorente, \& Cuenca. (Julio de 2014). Mapa de Poder Ecuador. Poder online de los políticos. Recuperado de http://www.mapadepoderecuador. com/

López, M. (2012). Twitter como instrumento de comunicación política en campaña: Elecciones Generlales 2011. Cuadernos de Gestión de Información, 69-84.

Lüfkens, M. (28 de abril de 2015). Twiplomacy study 2015. Twiplomacy.com. Recuperado de http://twiplomacy.com/blog/twiplomacy-study-2015/

Martín, M. A. (2004). Ciberdemocracia y opinión pública, "Iuces y sombras.". Palabra Clave (10), 85-99. Recuperado de http://palabraclave.unisabana.edu.co/index.php/palabraclave/article/view/434/572

Menéndez, M. (2011). Las redes sociales y su efecto político: ¿Nuevas fuentes ovejunas digitales? Telos (89), 74-83. Recuperado de https://telos. fundaciontelefonica.com/url-direct/pdf-generator?tipoContenido=articuloTelos\&idContenido=2011102411390001\&idioma=es

ONU critica al presidente ecuatoriano Rafael Correa por censurar a la prensa. (20 de junio de 2012). El Universo. Recuperado 01 abril 2016, de http://www.eluniverso.com/2012/06/20/1/1355/onu-critica-presidente-ecuatoriano-rafael-correa-censurar-prensa.html

Orihuela, J. L. (16 de abril de 2011). Políticos en campaña y Redes Sociales. Recuperado 01 de abril 2016, de https://www.ecuaderno.com/2011/ 04/16/politicos-en-campana-y-redes-sociales/

Posada, L. (2011). MIRA: Internet, participación y democracia. Las nuevas tecnologías y la reconexión con el ciudadano. Civilizar. Ciencias Sociales y Humanas, 11(20), 57-74.

Resina, J. (2010). Ciberpolítica, redes sociales y nuevas movilizaciones en España: el impacto digital en los procesos de deliberación y participación ciudadana. Mediaciones Sociales (7), 143-164.

Rodriguez, R. \& Ureña, D. (2011). Diez razones para el uso de Twitter como herramienta en la comunicación política y electoral. Comunicación y pluralismo (10), 89-116. ISSN 1885-8201

Sánchez, J. R. (2008). perspectivas de la informació en internet; ciberdemocraca,redes sociales y web semántica. Zer. Revista de Estudios de Comunicación, 13(25), 61-81. 
Sandoval-Almazán, R. \& Gil-García, JR. (2014). Towards cyberactivism 2.0? Understanding the use of social media and other information technologies for political activism and social movements". Government Information Quarterly, 31 (3), pp. 365-378. doi:10.1016/j.giq.2013.10.016

Sampedro, V. y Resina, J. (2010). Opinión pública y democracia deliberativa en la Sociedad Red. Ayer, Revista de Historia Contemporánea, 4(80), 139-162. ISSN: 1134-2277

Segado-Boj, F., Díaz-Campo, J. \& Lloves-Sobrado, B. (2015). Líderes latinoamericanos en Twitter. Viejas costumbres para nuevos medios en tiempos de crisis políticas. Revista Latina de Comunicación Social, 70, 156174. doi:10.4185/RLCS-2015-1040

Suh, B., Hong, L., Pirolli, P. \& Chi, E. H. (2010, August). Want to be Retweeted? Large Scale Analytics on Factors Impacting Retweet in Twitter Network. In Social computing (socialcom), IEEE second international conference ON (pp. 177-184). IEEE. doi:10.1109/SocialCom.2010.33

Toral, A. M. (2013). Política 2.0, alcances, penetraciones y limitaciones en la realidad ecuatoriana. (Tesis de Maestría en Comunicación y Marketing. Universidad del Azuay, Cuenca). Recuperado de http://dspace.uazuay. edu.ec/handle/datos/3330

Towner, T. L. (2013): "All political participation is socially networked?: New media and the 2012 election". Social Science Computer Review, 31 (5), pp. 527-541. doi:10.1177/0894439313489656

Twiplomacy. (26 de noviembre de 2015). Twiplomacy. Recuperado de http:// twiplomacy.com/blog/twiplomacy-study-2014-update/

Vacas, F. (2013). Gobierno y ciudadanía: Nodos en la red. En L. Elizalde, \& M. Riorda (Edits.), Comunicación Gubernamental 360. Buenos Aires: La Crujía.

Valenti, P., Lopez, R., Riorda, M., Straface, F. \& Santamaria, M. (2015). El goberauta latinoamericano. Estudio del perfil de los gobernantes latinoamericanos en redes sociales. Recuperado de https://publications.iadb. org/bitstream/handle/11319/6956/ICS_DP_Resumen_Ejecutivo_El_gobernauta_latinoamericano.pdf?sequence $=1$

Waisbord, S. (2013). America Media policies and the blindspots of media globalization: insights from Latin. Media Culture Society, 35(1), en., 132138. doi:10.1177/0163443712464567 